\title{
ANALISIS STUDI JARINGAN KOMUNIKASI KELUARGA KERAJAAN SINGHASARI BERDASARKAN SENTRALITAS AKTOR
}

\author{
Oleh: \\ Ritdza Gianjar Laiqi, Antoni, dan Sanggar Kanto \\ Prodi S2 Ilmu Komunikasi, Fakultas Ilmu Sosial dan Ilmu Politik, Universitas \\ Brawijaya \\ E-mail: gian.laiqi@gmail.com, ant_ui@yahoo.com,sanggar.fisip@ub.ac.id.
}

\begin{abstract}
Intisari
Posisi aktor dalam jaringan komunikasi tidak dipengaruhi oleh atribut yang dibawanya. Ken Arok merupakan tokoh penting dalam perkembangan kerajaan Singhasari, namun terdapat aktor-aktor lain yang memiliki pengaruh dalam jaringan komunikasi keluarga kerajaan Singhasari. Aktor-aktor ini dipengaruhi oleh posisinya dalam level sentralitas. Untuk mengetahui posisi aktor berdasarkan level sentralitas, dibutuhkan program UCINET 6 versi 6.629. Melalui program UCINET maka dapat terlihat aktor mana yang paling dominan dan yang paling berpengaruh dalam jaringannya. Selain itu juga, melalui program UCINET pada penelitian ini, ditemukan bahwa terdapat satu aktor dapat memiliki dua posisi sentralitas.
\end{abstract}

Kata kunci: Jaringan komunikasi, Aktor, Sentralitas aktor

\begin{abstract}
The position of the actor in the network communication is not affected by the attributes it carries. Ken Arok is an important figure in the development of Singhasari kingdom, but there are other actors who have influence in the network communications of the royal family Singhasari. These actors are influenced by their position within the centrality level. To know the position of actors based on centrality level, UCINET 6 version 6.629 is required. Through the UCINET program it can be seen which actors are the most dominant and the most influential in the network. In addition, through the UCINET program in this study, it was found that one actor can have two centrality positions.
\end{abstract}

Key words: Network communication, Actor, Centrality actor

\section{A. PENDAHULUAN}

Para raja di Nusantara khususnya di tanah Jawa pada masa lalu menggunakan garis keturuannya sebagai alat untuk menunjukkan kemajuan dan wilayah kekuasaan (Olthof, 2014). Namun tidak dengan Kerajaan Singhasari. Singhasari yang dikenal Tumapel 
merupakan wilayah bawahan Kadiri yang dipimpin oleh Akuwu Tunggul Ametung sebelum oleh Ken Arok menggulingkan Kertajaya (Achmad, 2016). Ken Arok berhasil menggulingkan Kertajaya pada tahun 1222 di sekitar desa Ganter (Achmad, 2016).

Keberhasilan Ken Arok, menjadikan dia sebagai raja pertama Kerajaan Singhasari. Kerajaan Singhasari yang berdiri selama 70 tahun tidak lepas dari intrik politik di lingkungan istana. Intrik politik, kekuasaan, dan power ini tentunya memiliki suatu keterhubungan antar indiviu yang mengalaminya. Hubungan, keterikatan, struktur atau utilitas sosial merupakan hal pokok dalam penelitian jaringan sosial (Kilduff \& Brass, 2010). Hubungan sosial yang terjalin menjadi suatu ikatan bukan merujuk pada berbagai entitas melainkan pada satu entitas (Bojanowski \& Corten, 2014).

Hubungan yang terus berkembang dan saling berkaitan merupakan suatu proses jaringan. Jaringan sosial merupakan struktur sosial yang terbentuk dari suatu hubungan antar individu atau institusi yang memiliki tujuan sama (Baird \& Gray, 2014). Jaringan sosial yang didalamnya terdapat proses pertukaran informasi dan pembentukan makna dapat membangun suatu hubungan komunikasi.

Penelitian ini merujuk pada penelitian keluarga Medici di wilayah Eropa. Keluarga Medici memerintah Florance pada tahun 1430-an hingga 1730-an (Weisz, Matucci-Cerinic, Lippi, \& Albury, 2011). Padgett dan asistennya mengumpulkan data untuk melihat jaringan sosial keluarga kaya ini melalui hubungan partinial, pernikahan, lingkungan, kekayaan pribadi, jabatan politik, kenggotaan kelas sosial (Padgett \& McLean, 2011). Penelitian Padget dan McLean menyoroti aliran kredit antar bank, aliran dana produksi kain wol dan sutra menggunakan aplikasi Pajek.

Berbeda dengan penelitian Padget dan McLean yang menyoroti aliran dana keluarga bangsawan untuk mengetahui jaringan sosial. Pada penelitian ini, peneliti berfokus pada sistem kekuasaan atau power keluarga kerajaan Singhasari dengan aplikasi UCINET.

Melalui deskripsi di atas, peneliti membuat kesimpulan. Perlu adanya penelitian terkait studi jaringan komunikasi keluarga kerajaan. Berdasarkan kesimpulan tersebut akan memunculkan suatu keingintahuan. Bagaimana studi jaringan komunikasi keluarga Kerajaan Singhasari melalui kekuasaan atau power.

\section{B. TINJAUAN PUSTAKA}

\section{Studi Jaringan Komunikasi}

Rogers \& Kincaid (1981) menjelaskan bahwa tujuan dari penelitian jaringan komunikasi yaitu untuk mengetahui fenomena akan interaksi antar individu pada sistem sosial serta mengidentifikasi dampak yang ditimbulkannya. Hal ini juga dikuatkan oleh Eriyanto (2014) yaitu melalui analisis jaringan komunikasi maka dapat diketahui posisi dan kekuatan aktor dalam struktur sosial. Aktor merupakan salah satu elemen penting dalam analisis studi jaringan komunikasi. Analisis jaringan komunikasi memfokuskan perhatian pada aktor dalam suatu jaringan (Eriyanto, 2014). Posisi tiap aktor dipengaruhi oleh hubungnnya dengan aktor lain. Untuk mengetahui posisi tiap aktor maka dibutuhkan pengukuran sentralitas aktor. Pengukuran tersebut adalah sentralitas tingkatan (degree) 
menggambarkan popularitas tiap aktor; kedekatan (closeness) menggambarkan kedekatan antar aktor; keperantaraan (betweenness) posisi aktor sebagai perantara hubungan antar aktor lainnya; eigenvektor (eigenvector) menggambarkan seberapa penting aktor dalam kelompoknnya (Eriyanto, 2014).

Posisi sentralitas aktor seperti yang disebutkan di atas, dapat diketahui berdasarkan peranannya dalam jaringan. Pace \& Faules (2006) menyebutkan klik, kumpulan aktor yang saling terhubung; isolate, aktor yang menarik diri dari jaringannya; bridge, aktor yang sebagai penjembatan dengan kelompok di luar jaringannya; liasion, aktor yang bukan merupakan anggota jaringan namun sebagai penjembatan antar kelompok; gate keepers, aktor yang menyalurkan informasi; opinion leader, aktor yang berpengaruh pada kelompoknya; cosmopolites, aktor yang menghubungkan kelompoknya dengan lingkungan sekitar. Selain itu terdapat cutpoints yangmana aktor sebagai pelekat dari jaringannya (Borgatti \& Dejody 2013). Jika tidak terdapat aktor ini maka jaringan komunikasi akan terberai.

\section{METODOLOGI}

Penelitian ini menggunakan teknik analisis data yang lebih berfokus pada jaringan utuh pada level aktor. Penelitian ini menggunakan metode penelitian deskriptif kualitatif. Tipe penelitan kualitatif adalah bertujuan untuk menjelaskan suatu kejadian secara mendalam dengan mengumpulkan data secara mendalam dengan deskripsi yang secara terarah, nyata, dan terpecaya (Kriyantono, 2014). Pendekatan historis dipilih oleh peneliti karena fenomena komunikasi telah terjadi pada masa lampau. Teknik pengumpulan data menggunakan studi pustaka. Studi pustaka merupakan teknik pengumpulan data melalui penelaahan pada buku, literatur, catatan, dan laporan yang memiliki keterkaitan dengan penelitian peneliti (Nazir, 1985). Setelah pengumpulan data telah dilakukan, untuk membantu menganalisis data peneliti menggunakan UCINET 6 versi 6.629.

\section{PEMBAHASAN}

Berikut ini merupakan studi jaringan komunikasi keluarga Kerajaan Singhasari berdasarkan kekuasaan atau power:

\section{Silsilah Keluarga vs Studi Jringan Komunikasi}

Analisis jaringan komunikasi tentunya berbeda dengan silsilah keluarga atau struktur organisasi. Untuk mempermudah pemahaman berikut ini merupakan ilustrasi perbedaan silsilah keluarga atau struktur organisasi dengan jaringan komunikasi.

Menurut Lipnack dan Stamps (1994) tipe orgnisasi dibedakan menjadi hierarkis, birokrasi, dan jaringan (Eriyanto, 2014). Organisasi yang dilaksanakan berdasarkan hierarkis menunjukkan komunikasi dari atas ke bawah. Sedangkan tipe birokrasi menunjukkan komunikasi yang setara. Kedua tipe ini juga tergambar jika kita melihat silsilah keluarga. Bentuk komunikasi yang terlihat dalam silsilah tergambar secara vertikal dari kakek ke cucunya atau horizontal dari ayah dengan paman. 


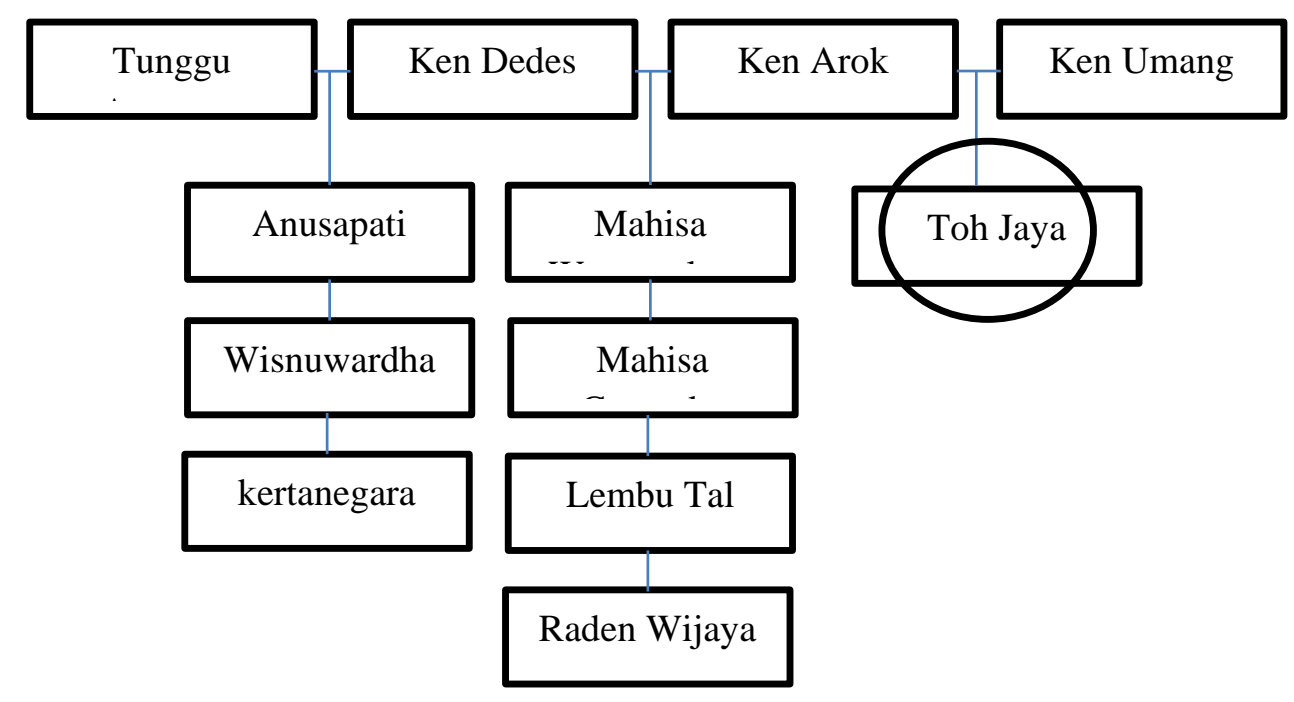

Gambar 1: Silsilah Keluarga Kerajaan

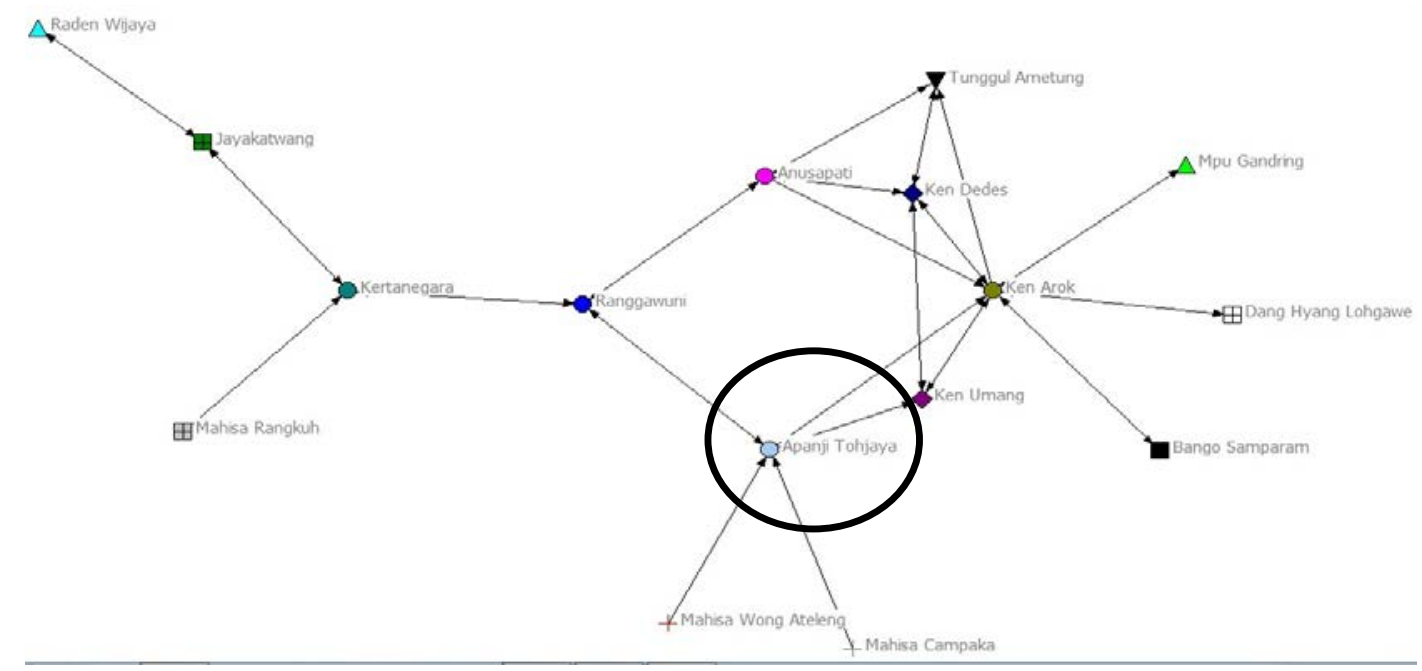

Gambar 2: Jaringan Komunikasi raja Kerajaan

Singhasari

Salah satu contoh berbedaan antara silsilah keluarga kerajaan Singhasari dengan jaringan komunikasi keluarga kerajaan Singhasari adalah posisi aktor Apanji Tohjaya. Gambar 1 memperlihatkan bahwa Apanji Tohjaya merupakan anak Ken Arok dan Ken Umang dan tidak ada penjelasan lebih lanjut menganai hubungannya dengan aktor lainnya. Sedangakan pada gambar 2 menunjukkan bahawa Apanji Tohjaya selain memiliki hubungan komunikasi dengan Ken Arok dan Ken Umang, juga berhubungan dengan Mahisa Wong Ateleng, Mahisa Campaka, serta Ranggawuni. Sehingga dapat diketahui walaupun Ranggawuni tidak terdapat pada silsilah keluarga, namun aktor ini memiliki 
keterikatan dengan Apanji Tohjaya. Melalui pada jaringan maka dapat diketahui aktor yang dominan pada struktur sosial. Dominasi ini muncul karena adanya hubungan antar aktor.

\section{Struktur Jaringan Komunikasi Keluarga Kerjaan Singhasari}

Jaringan kerajaan Singhasari ini menggambarkan hubungan antar aktor. Hubungan tersebut menunjukkan keterikatan antar aktor di dalamnya. Seperti yang dipaparkan pada bab pertama, bahwa intrik politik kerajaan Singhasari sangat berpengaruh pada hubungan antar aktor.

Tabel berikut menggambarkan aktor dan perannya dalam jaringan kerajaan Singhasari.

\begin{tabular}{|c|c|c|c|c|}
\hline Node & Nama Aktor & Atribut & Lambang & Warna \\
\hline 1. & Ken Arok & Raja & Lingkaran & Hijau lumut \\
\hline 2. & Ken Dedes & Istri & Ketupat & Biru \\
\hline 3. & Tunggul Ametung & Pemimpin Tumapel & Segitiga & Hitam \\
\hline 4. & Ken Umang & Istri & Ketupat & Ungu \\
\hline 5. & Anusapati & Raja & Lingkaran & Merah muda \\
\hline 6. & Apanji Tohjaya & Raja & Lingkaran & Biru laut \\
\hline 7. & Ranggawuni & Raja & Lingkaran & Biru \\
\hline 8. & Mahisa Campaka & $\begin{aligned} \text { Putra mahisa wong } \\
\text { ateleng }\end{aligned}$ & Tanda plus & Hitam \\
\hline 9. & $\begin{array}{l}\text { Mahisa Wong } \\
\text { Ateleng }\end{array}$ & Anak Ken Arok & Tanda plus & Merah \\
\hline 10. & Kertanegara & Raja & Lingkaran & Toska \\
\hline 11. & Mahisa Rangkuh & Pemberontak Singhasari & Kotak & Putih \\
\hline 12. & Jayakatwang & Bupati Galenggelang & Kotak & Hijau \\
\hline 13. & Raden Wijaya & Raja Majapahit & Segitiga & Toska \\
\hline 14. & $\begin{array}{ll}\text { Dang } & \text { Hyang } \\
\text { Lohgawe } & \end{array}$ & Pendeta istana & Kotak & Putih \\
\hline 15. & Bango Samparam & Pemberontak Singhasari & Kotak & Hitam \\
\hline 16. & Mpu Gandring & Pembuat Keris & Segitiga & Hijau \\
\hline
\end{tabular}

Tabel 1. Aktor Jaringan Kerajaan Singhasari

Berdasarkan tabel di atas maka dapat diketahui posisi aktor berdasarkan tingkat sentralitas aktor dan pengaruhnya terhadap struktur jaringan komunikasi.

a. Sentralitas Tingkatan (Degree Centrality)

Sentralitas tingkatan (degree) menunjukkan popularitas aktor pada jaringan sosial (Eriyanto, 2014). Jumlah tingkatan aktor dilihat dari jumlah link atau arah panah. Link pada jaringan komunikasi bisa berupa indegree atau link yang mengarah ke aktor serta outdegree yaitu link yang keluar dari aktor. 


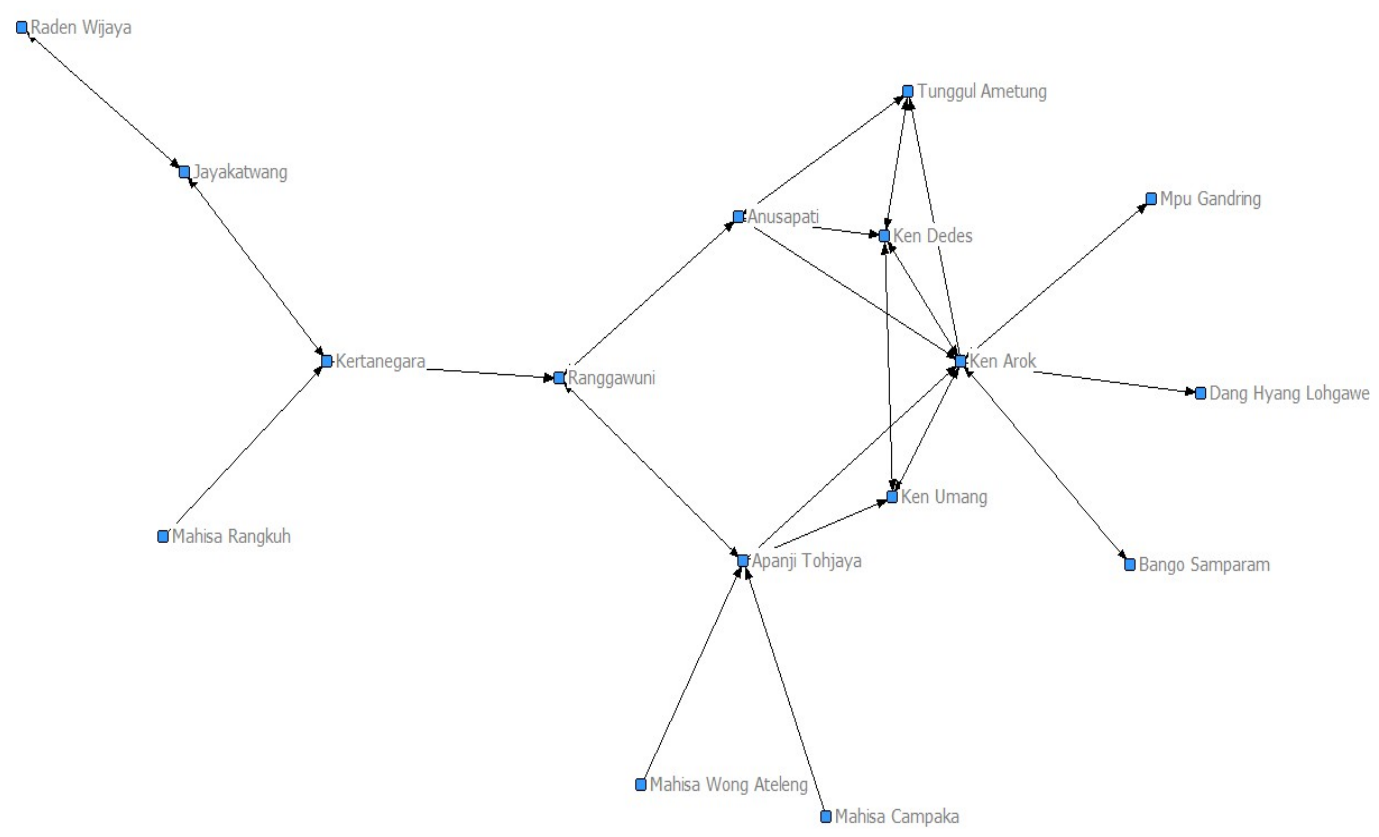

Gambar 3: Jaringan Komunikasi Keluarga

Pada jaringan komunikasi keluarga kerajaan Singhasari dapat diketahui bahwa total indegree dan outdegree sebanyak 16 link. Angka tingkat sentralitas tingkatan diukur berdasarkan skala 0 hingga 1 . Total sentralitas indegree adalah 0.2711 dan total sentralitas outdegree adalah 0.3422 . Aktor yang memiliki sentralitas tingkatan tinggi adalah Ken Arok. Outdegree Ken Arok adalah 0.4 dengan jumlah link sebanyak 6 ties. Indegree paling banyak juga terdapat pada aktor Ken Arok sebanyak 0.467 dengan jumlah 7 ties. Sedangkan untuk indegree 0 adalah Mahisa Campaka, Mahisa Wong Ateleng, dan Mahisa Rangkuh. Hal ini membuktikan bahwa tidak ada satupun aktor yang menghubungi ketiga aktor tersebut. Untuk nilai outdegree yang paling kecil adalah Mahisa Campaka, Mahisa Wong Ateleng, Raden Wijaya, Dang Hyang Lohgawe, Bango Samparam, serta Mpu Gandring dengan nilai 0.067 .

b. Sentralitas Kedekatan (Closeness Centrality)

Sentralitas kedekatan menggambarkan kedekatan tiap aktor dalam jaringannya (Eriyanto, 2014). Kedekatan tiap aktor dapat diketahui dari berapa tahapan tiap aktor untuk menjalin hubungan dengan aktor lain. Sentralitas kedekatan melihat aktor mana yang tercepat menjangkau aktor lainnya. Aktor yang memiliki tingkat sentralitas kedekatan rendah adalah Raden Wijaya dengan nilai 0.197. Sedangkan sentralitas kedekatan tinggi adalah Anusapati dengan nilai 0.319. Nilai terendah menunjukkan kedekatan antar aktor pada jaringan. Sehingga Raden Wijaya yang memiliki nilai terendah menunjukkan bahwa aktor ini memiliki kedekatan dengan aktor yang lain. Raden Wijaya hanya membutuhkan rata-rata 0.242 kali jalur untuk bisa menjalin hubungan dengan semua aktor yang ada di 
dalam jaringan. Walaupun Ken Arok memiliki tingkatan sentralitas tinggi, untuk menghubungi dengan aktor lainnya dalam jaringan komunikasi keluarga kerajaan, membutuhkan rata-rata 0.513 langkah. Raden Wijaya yang memiliki sentralitas kedekatan teridentifikasi sebagai cutpoint atau aktor yang mampu menjadi perekat dengan aktor lainnya.

c. Sentralitas Keperantaraan (Betweenness Centrality)

Posisi aktor dapat dilihat dari perantara antar aktor satu dengan lainnya melalui sentralitas keperantaraan (Eriyanto, 2014). Indeks sentralitas keperantaraan jaringan komunikasi keluarga kerajaan Singhasari adalah 32.444\%. Tingkat sentralitas keperantaraan tertinggi adalah Ranggawuni. Nilai sentralitas keperantaraan dengan nilai 0 adalah Mahisa Wong Ateleng, Mahisa Rangkuh, Mahisa Campaka, Raden Wijaya, Dang Hyang Lohgawe, Bango Samparam, dan Mpu Gandring. Nilai sentralitas 0 menunjukkan bahwa aktor tidak memiliki peran sebagai perantara dengan aktor lainnya. Berdasarkan analisis sentralis keperantaraan, peran Ranggawuni adalah sebagai liasion. Ranggawuni bukan merupakan anggota kelompok jaringannya namun berperan sebagai penjembatan antara kelompok jaringan.

d. Sentralitas Eigenvektor (Eigenvector Centrality)

Sentralitas eigenvektor yaitu melihat seberapa penting aktor dalam jaringannya (Eriyanto, 2014). Aktor yang memiliki nilai eigenvektor tertinggia adalah Ken Arok dengan nilai 0.543. Sedangkan aktor yang memiliki nilai eigenvektor terendah adalah Raden Wijaya dengan nilai 0.004. Nilai eigenvektor tinggi menunjukkan bahwa aktor tersebut memiliki peran penting dalam jaringannya.

\section{Level Aktor Sentralitas}

\begin{tabular}{llll}
\hline $\begin{array}{l}\text { Sentralitas } \\
\text { Tingkatan }\end{array}$ & $\begin{array}{l}\text { Sentralitas } \\
\text { Kedekatan }\end{array}$ & $\begin{array}{l}\text { Sentralitas } \\
\text { Keperantaraan }\end{array}$ & $\begin{array}{l}\text { Sentralitas } \\
\text { Eigenvektor }\end{array}$ \\
Ken Arok & Raden Wijaya & Ranggawuni & Ken Arok \\
\hline
\end{tabular}

Tabel 2. Level Aktor Sentralitas

Ken Arok memiliki nilai sentralitas tingkatan tinggi dan sentralitas eigenvektor tinggi. Hal ini menunjukkan bahwa Ken Arok merupakan aktor yang memiliki posisi dominan dalam penyebaran arus informasi kepada aktor lain. Hal ini juga dipengaruhi oleh modal sosial aktor. Coleman (1990) tiga modal aktor adalah modal fisik seperti kesehatan, bentuk tubuh; modal manusia seperti kepribadian, kepandaian; modal sosial. Modal sosial sangat berpengaruh terhadap analisis jaringan komunikasi. Melalui modal sosial, aktor dapat diterima oleh lingkungan sosialnya. Hal inilah yang juga terjadi pada aktor Ken Arok. Penelitian jaringan komunikasi tidak melihat atribut dari aktor seperti status sosialnya (Eriyanto, 2014). Penyebab Ken Arok memiliki sentralitas tingkatan dan sentralitas eigenvektor tinggi bukan karena aktor ini adalah seorang raja. Melainkan jaringan yang dibentuk oleh Ken Arok dalam menjalin relasi dengan aktor lainnya.

Sentralitas kedekatan diduduki oleh Raden Wijaya yang merupakan pendiri kerajaan Majapahit. Hal ini karena Raden Wijaya memiliki kedekatan menjangkau aktor lainnya lebih cepat daripada aktor lainnya. Sedangkan sentralitas keperantaraan tertinggi adalah Ranggawuni. Pada gambar 3 menunjukkan bahwa Ranggawuni merupakan aktor yang 
menjadi penghubung antara aktor dalam jaringannya dengan aktor di luar jaringannya. Ranggawuni memiliki posisi kuat dan menguntungkan karena menjadi penghubung dua kelompok yang berbeda pada jaringan komunikasi.

\section{E. KESIMPULAN}

Berdasarkan hasil penelitian tentang studi jaringan komunikasi berdasarkan kekuasaan atau power, penelitian mendapatkan kesimpulan sebagai berikut:

1. Posisi sentralitas aktor sangat berpengaruh terhadap jaringan komunikasi keluarga kerajaan Singhasari.

2. Posisi sentralitas aktor tidak dipengaruhi karena latar belakang aktor tersebut adalah seorang raja. Melainkan bagaimana aktor dalam menyalurkan informasi kepada aktor lainnya.

\section{DAFTAR PUSTAKA}

Achmad, S. W. (2016). Sejarah Kerajaan-Kerajaan Besar di Nusantara. Araska. Yogyakata Achmad, S. W. (2016). Politik Dalam Sejarah Kerajaan Jawa. Araska. Yogyakarta

Adji, K. B. (2016). Di Balik Pesona dan Sisi Kelam Singhasari dari Masa Kejayaan, Keruntuhan Hingga Kutukan Mpu Parwa dan Mpu Gandring. Araska. Yogyakarta

Baird, T. D., \& Gray, C. L. (2014). Livelihood diversification and shifting social networks of exchange: A social network transition? World Development, 60, 14-30. https://doi.org/10.1016/j.worlddev.2014.02.002

Bojanowski, M., \& Corten, R. (2014). Measuring segregation in social networks. Social Networks, 39(1), 14-32. https://doi.org/10.1016/j.socnet.2014.04.001

Borgatti, Stephen P. And Rich Dejody, 2013. "Basic Concepts in Social Network Analiysis” Makalah Workshop SNA, 5 Juni 2013. Diakses dari https://sites.google.com/site/uklinkcenter.

Coleman, J. (1990). Foundation of Social Theory. Cambridge, MA: Harvard University Press.

Denney, A. S., \& Tewksbury, R. (2013). How to Write a Literature Review. Journal of Criminal Justice Education, 24(2), 218-234. https://doi.org/10.1080/10511253.2012.730617

Eriyanto. (2014). Analisis Jaringan Komunikasi. Jakarta: Prenamedia Gorup

Kilduff, M., \& Brass, D. J. (2010). Organizational Social Network Research: Core Ideas and Key Debates. The Academy of Management Annals, 4(1), 317-357. https://doi.org/10.1080/19416520.2010.494827

Notosusanto, N. (1984). Masalah Penelitian Sejarah Kontemporer. Jakarta: Idayu Press.

Olthof, W. L. (2014). Babad Tanah Jawi Mulai dari Nabi Adam Sampai Runtuhnya Mataram. Pustaka Narasi

Pace, R. W., \& Faules, D. F. (2006). Komunikasi Organisasi. Bandung: Remaja Rosdakarya. 
Padgett, J. F., \& McLean, P. D. (2011). Economic Credit in Renaissance Florence. The Journal of Modern History, 83(1), 1-47. https://doi.org/10.1086/658247

Rogers, E. M \& Kincaid, D. L. (1981). Communication Network: Toward a New Paradigm for Research. New York: The Free Press.

Weisz, G. M., Matucci-Cerinic, M., Lippi, D., \& Albury, W. R. (2011). The ossification diathesis in the Medici family: DISH and other features. Rheumatology International, 31(12), 1649-1652. https://doi.org/10.1007/s00296-010-1563-6 